\title{
ESPAÇO GEOGRÁFICO E TERRITÓRIO, SOCIEDADE URBANA- INDUSTRIAL E DESENVOLVIMENTO SUSTENTÁVEL: UM ENSAIO TEÓRICO-METODOLÓGICO EM GEOGRAFIA
}

\author{
Guilherme Ribeiro* \\ Leandro Dias de Oliveira ${ }^{* *}$
}

\begin{abstract}
Resumo
Este ensaio pretende discutir, à luz da Geografia, os nexos entre o desenvolvimento sustentável, a crise da sociedade urbana-industrial e os conceitos de espaço geográfico e território. Trata-se de articulações teórico-metodológicas elaboradas de um ponto de vista crítico face a determinadas interpretações acerca do espaço geográfico e do desenvolvimento sustentável.
\end{abstract}

Palavras-chave: espaço geográfico; território; sociedade urbana-industrial; desenvolvimento sustentável; geografia

\section{Résumé}

Sous le point du vue de la Géographie, cet essai veut discuter les liens parmi le developpément soutenable, la crise de la société urbaine et industrielle et les concepts de l'espace géographique et de territoire. S'agit-il des connexions théoriques et méthodologiques critiques engendrées face à des interprétations autour de l'espace géographique et du dévellopement durable.

Mots-clé: espace géographique; territoire; société urbaine et industrielle; dévellopement durable; géographie

\section{Introdução}

Uma das primeiras preocupações de um geógrafo, independente do tema no qual ele estiver debruçado, deve ser o tratamento do espaço geográfico. $\mathrm{O}$ fato de enunciarmos espaço geográfico e não espaço já é indicativo de alguma coisa: referimos-nos particularmente à polissemia do conceito, podendo este ser o espaço arquitetônico, físico, mental. Queremos, com esta distinção, sublinhar a especificidade do espaço da Geografia, que aqui podemos definir como sendo o conjunto de coisas materiais construídas pelo trabalho dos homens em sociedade através da transformação da natureza, que é a matéria-prima de sua produção. Destarte, nos distanciamos de uma leitura que o vislumbre como sendo:

\footnotetext{
* Doutor em Geografia pela UFF, com doutorado sandwich pela Universidade de Paris - Sorbonne (Paris IV). Prof. Adjunto I de Geografia do Instituto de Ciências da Sociedade e Desenvolvimento Regional da UFF - Campos dos Goytacazes.

*** Mestre em Geografia pela UERJ e Doutorando em Geografia pela UNICAMP. Professor Assistente do Departamento de Geociências da UFRRJ - Universidade Federal Rural do Rio de Janeiro, Seropédica - RJ.
} 
[1] um dado da natureza, como os mares, rios, montanhas, geleiras e desertos, onde o espaço geográfico preexiste ao Homem e deixa de ser uma consequência de seu trabalho;

[2] um conjunto de pontos numa superfície, sendo apenas um sinônimo de distância, geometrizados e matematizados como as coordenadas "geográficas", numa conceituação cujo desdobramento imediato significa que o tempo suprime o espaço, a cronopolítica substitui a geopolítica ${ }^{1}$;

[3] algo anterior às sociedades, ou, para utilizar uma expressão bastante conhecida, um dado a priori e independente da matéria, vazio e absoluto ${ }^{2}$.

Todas estas definições persistem, principalmente, na fala de determinados historiadores e cientistas sociais (RIBEIRO, 2004, 2008), conformando uma situação que dificulta a construção de um discurso especificamente geográfico e de uma identidade epistemológica que faça com que os geógrafos se reconheçam enquanto cientistas envolvidos num mesmo campo de atuação. Neste artigo, a análise de uma concepção contemporânea - o Desenvolvimento Sustentável - nos permite refletir sobre um conceito de espaço geográfico mais dinâmico, ao mesmo tempo em que interpretamos as reais implicações de um discurso hegemônico em sua gestão.

\section{Espaço Geográfico e Território Nacional: um recorte conceitual}

Inicialmente, poderíamos asseverar que o espaço geográfico é um conjunto de coisas materiais. Tais coisas podem ser as universidades, as igrejas, as estradas, os túneis, shoppingcenters, aeroportos, pontes, edifícios, entre outros. Podemos chamá-los de objetos geográficos. Isolados, entretanto, nada significam se não levarmos em consideração o seu entorno. Em outras palavras, metodologicamente a Geografia não enxerga apenas $a$ universidade, $a$ igreja, $o$ aeroporto, $o$ shopping, mas sim os múltiplos sentidos e significados que as sociedades atribuem a estes objetos que, em conjunto $e$ inter-relacionados, configuram o espaço geográfico. Assim, da mesma forma que as sociedades são um produto da História, ou seja, um resultado do que os homens vêm construindo no decorrer do tempo, elas também são um produto da Geografia, na medida em que não existe sociedade a-espacial, cuja configuração possa prescindir desse conjunto de objetos materiais que constituem a própria sociedade.

\footnotetext{
${ }^{1}$ Tal como podemos ler em Virilio, para quem nos tempos atuais a geopolítica deve ser substituída pela cronopolítica (VIRILIO, 1993 [1984]). Uma crítica a essa perspectiva foi levantada por Ribeiro (RIBEIRO, 2008).

${ }^{2}$ Para um aprofundamento destas concepções de espaço, ver Kant (KANT, 2002 [1781]) e Newton (NEWTON, 1979).
} 
Espaço (geográfico), tempo e ser social: a tríade ontológica de que nos fala Soja (SOJA, 1993 [1992]) é também a trindade epistemológica para a re-formulação do saber geográfico.

Tal reformulação passa fundamentalmente por uma importantíssima propriedade do espaço geográfico: a inércia dinâmica (SANTOS, 1978). Os objetos geográficos são fixos mas, dados os significados que possuem para os homens, são dotados da capacidade de gerarem fluxos graças a um "sistema de ações" (SANTOS, 2002 [1996]). Tais objetos não se movem, porém participam "ativamente" da dinâmica societária ${ }^{3}$. As aspas se justificam porque apenas o Homem é dotado da capacidade de ação, de transformação, de modificação; todavia, não é o espaço geográfico um mero reflexo da sociedade, algo inerte que os homens constróem e cuja influência em seu cotidiano é irrelevante. Dito de outra forma, embora o espaço geográfico como um todo seja parte integrante do andamento das sociedades, o Homem é o único capaz de movimentá-lo, não possuindo o espaço geográfico "leis autônomas" à sociedade (SOUZA, 1988). É nessa “simbiose” sociedade- espaço geográfico que a Geografia sublinha sua relevância no âmbito das Ciências Humanas: qual seja, como as sociedades, ao mesmo tempo em que constroem seus espaços geográficos, acabam por se modificarem, engendrando novas possibilidades e um novo dinamismo social.

Assim, podemos apreender uma das formas de articulação do espaço geográfico com o território. Entendendo o território em sua acepção mais recorrente, que o associa ao EstadoNação ${ }^{4}$, não é possível concebê-lo sem seu respectivo espaço geográfico. Cada formação sócio-espacial contém um dado arranjo espacial que lhe é particular (SANTOS, 1977), resultado da atuação de diversos agentes nas mais variadas escalas. Desde os vetores exógenos, de cunho internacional, passando pela escala do Estado - cuja intervenção (independente do aspecto privilegiado) se dá de forma direta, e não indiretamente, como se fosse uma prática secundária ${ }^{5}$ - até a escala local, é sempre uma interação escalar que

\footnotetext{
${ }^{3}$ Reforçando o fato de ter sido a maior fonte de inspiração de Milton Santos, Lefebvre afirma que "O espaço e a política do espaço ‘exprimem' as relações sociais, mas reagem sobre elas” (LEFEBVRE, 1999 [1970]).

${ }^{4} \mathrm{O}$ que não significa que esta concepção é a única possível, pois resultaria numa redução teórica inaceitável, nem tampouco que estamos corroborando com o status quo porque esta é a acepção que mais serviu como ideologia de Estado. Para um debate que contempla estas e outras interrogações, consulte Souza (SOUZA, 1995) e, sobretudo, Haesbaert (HAESBAERT, 2007 [2004]).

${ }^{5}$ Numa abordagem que parece ora separar, ora unir o espaço geográfico com a dimensão econômica e mesmo com a socidade, lemos em Barrios que "O Estado incide no nível das práticas econômicas por duas vias: diretamente, cumprindo funções econômicas básicas; e indiretamente, por meio dos processos de planejamento" (BARRIOS, 1986:11). Noutra passagem dirá que "Mudando pouco ou nada a curto prazo, o espaço transformado oferece menos dificuldade para a conceitualização e a análise quantitativa do que as variáveis de natureza social. Compare-se, por exemplo, a complexidade que envolve definir e medir o grau de heterogeneidade cultural de uma comunidade frente a
} 
devemos ter em mente (VIDAL DE LA BLACHE, 2002 [1896]; SMITH, 2002). Isto torna mais difícil o trabalho do geógrafo, porém constitui-se num pressuposto para a apreensão da totalidade e, principalmente, dos fenômenos em tempos de globalização, que quase sempre ocorrem de maneira transescalar (CASTELLS, 1999; MASSEY, 2008 [2005]).

Como o próprio significado de território possui concomitantemente a dimensão de natureza enquanto força produtiva e poder de organização (QUAINI, 1979), seria o território uma síntese do diverso, contendo em cada parcela uma combinação ímpar. Dizemos isso porque, por mais que o status quo insista em impor no território uma única e irrestrita ordem, esta mesma ordem traz consigo a possibilidade de uma outra ordem, uma desordem para o poder hegemônico mas que, para os dominados, representa o modo como estes recebem, acolhem esta ou aquela imposição. O que estamos falando aqui é de um "contra-espaço" (MOREIRA, 2001, 2002), que seria uma tentativa de contraponto aos interesses hegemônicos, uma manifestação popular que, se nem sempre visa romper com o poder constituído, ao menos indica, abre caminhos para a possibilidade de uma outra apropriação do espaço geográfico. Como exemplos desse contra-espaço, podemos citar as favelas, resultado direto de uma política de segregação espacial, mas que atualmente são utilizadas como locus de um poder paralelo que desafia o status quo. As rodovias planejadas para o rápido escoamento da produção e movimentação de capital não são também passíveis de serem inteligentemente apropriadas para a realização de uma greve de caminhoneiros, causando engarrafamentos gigantescos que prejudicariam as estratégias tanto de grandes empresas quanto de turistas ${ }^{6}$, impedindo a fluidez do território?

Outra possibilidade dada pelo cruzamento dos conceitos de território e espaço diz respeito à relação estabelecida entre a natureza e o capitalismo que, mormente a partir do último quartel do século XX, vem sofrendo intensas transformações. Fóruns mundiais vêm sendo promovidos (Conferência de Estocolmo, ECO-92) e documentos internacionais são elaborados (Protocolo de Kyoto, Agenda 21, Carta da Terra). Tudo isso em virtude de uma provável obliteração de certos recursos naturais, como o petróleo e a água, resultado de uma incessante destruição da natureza em nome do capitalismo, da modernização e do progresso urbano-industrial. Faz-se mister, portanto, um novo olhar sobre a natureza, cuja proteção se

tarefa menos problemática de estabelecer o número de seus habitantes residentes a moradias insalubres" (idem, p.17). Ora; é a isto que se resume a análise do espaço geográfico? Por acaso ele não é de natureza eminentemente social?

${ }^{6}$ No momento em que escrevemos (agosto de 2010), a Grécia, um dos destinos mais procurados para a prática do turismo durante o verão europeu, se viu diante de uma greve de caminhoneiros que paralisou o país e afetou tanto o abastecimento de mercadorias e combustíveis quanto o ir e vir de turistas em seu território. 
insere como parte de garantia do "nosso futuro comum": é o desenvolvimento sustentável, estratégia global baseada num discurso falacioso de "proteção da natureza" cuja finalidade é, inequivocamente, a reprodução da mesma enquanto um repositório de lucros para o capital garantindo assim a reprodução do próprio capitalismo.

\section{Desenvolvimento Sustentável: problematizações}

A concepção de Desenvolvimento Sustentável emerge a partir da necessidade global de reflexão sobre o modelo de desenvolvimento capitalista adotado pelos países centrais e periféricos. Se na Conferência de Estocolmo (1972), bastante influenciada pelo Clube de Roma, ocorreu um dissenso entre países do centro e da periferia nas soluções para o veloz e destrutivo ritmo de produção do capitalismo mundial, somente na década seguinte, com um documento das Nações Unidas — o Relatório Brundtland (1987) — foi formulada uma idéia consensual, onde o Desenvolvimento Sustentável aparecia como resolução incontornável, indelével e incontestável para as catástrofes sócio-ambientais emergentes e para a obliteração dos valiosos recursos da natureza. Neste panorama, sua consecutiva celebração na Conferência do Rio de Janeiro (1992) foi marcada pela assinatura do receituário Agenda 21 onde, a partir de então, todos os países (centrais ou periféricos) passariam a adotar os seus pressupostos e implementar suas estratégias (OLIVEIRA, 2006, 2007, 2009).

O Desenvolvimento Sustentável significa então, antes de mais, a defesa do uso racional da natureza, agora entendida enquanto combustível primaz de real necessidade para a manutenção do perfeito funcionamento da máquina capitalista. Este processo exploratório da natureza pelo capital através da execução das riquezas naturais pela ação industrial deverá, segundo a cartilha do pensamento dominante, ser contornado de duas formas: pela evolução técnica, através de mecanismos de filtragem da poluição; e pelo uso metódico dos "recursos" cada vez mais escassos - guardando para um mercado futuro em espaços específicos (RODRIGUES, 1992) —, a fim de que seja prolongada a existência da fonte natural da máquina capitalista, que jamais pode diminuir a produção. Não há dúvidas que está em curso um processo de reestruturação produtiva, onde o "desenvolvimento calcado no processo único de industrialização e na ideologia do progresso" é adaptado para um modelo de "desenvolvimento sustentável, com tecnologia clean e uma ideologia de proteção da natureza” (OLIVEIRA, 2006, grifo nosso). 
Segundo a argumentação de Ruy Moreira, a presente "civilização geológica", cuja referência é o processo repetitivo e mecanicista da revolução industrial baseada no uso de "recursos" naturais esgotáveis, como os metais básicos, o carvão e petróleo, encontra-se em pleno declínio. Alicerçada na utilização inconseqüente de combustíveis fósseis e sujeitando todo o trabalho produtivo à repetição constante, o modelo em tela consolidou a hegemonia burguesa e reproduziu a realidade com a primazia de seus interesses de classe. Esta racionalidade estaria sendo progressivamente substituída por uma nova relação sociedadenatureza, pois este momento de crise do mundo moderno advém justamente das limitações de um modelo cuja lógica é aprisionar os ciclos naturais, suprimir ao máximo as iniciativas dissonantes e mecanizar todo o espaço como uma grande fábrica multi-setorial (MOREIRA, 2004). Assim, a urgência causada pelo rareamento da matriz fóssil, que funciona como nutriz energética da sociedade industrial, colocou este axioma em xeque, o que possibilitou a tentativa de construção de um novo paradigma - complexo, holístico, sistêmico, biológico, sustentável $^{7}$ - , fruto de uma necessidade de mutação do sistema capitalista.

Baseada em tecnologias flexíveis, novas fórmulas de apropriação da força de trabalho e utilização de combustíveis a partir de fontes biológicas, a gestação de um corpus epistêmico para este paradigma passa indubitavelmente pela edificação de um re-ordenamento global.

\footnotetext{
${ }^{7}$ As bases conceituais deste novo paradigma em gestação são difusas e muitas vezes anacrônicas. Edgar Morin aponta a necessidade de um paradigma baseado na complexidade alicerçado em uma transdisciplinaridade, onde as matrizes científicas ora separem-se, ora associem-se de acordo com a emergência da realidade (MORIN, 1996) e superem a divisão em ciências naturais e sociais (SANTOS, 1996 [1987]). Além de transdisciplinar, Ilya Prigogine e Isabelle Stengers afirmam que "a ciência de hoje não pode mais dar-se o direito de negar a pertinência e o interesse de outros pontos de vista e, em particular, de recusar compreender os das ciências humanas, da filosofia e da arte" (PRIGOGINE \& STENGERS, 1991 [1979]). Esta constante necessidade de consenso / dissenso e associação / ruptura deve-se ao fato de que o entendimento deve ser holístico e sistêmico, "capaz de perceber as inter-relações entre os diferentes processos que incidem e caracterizam seu campo problemático" (LEFF, 2001 [2000]). Em outras palavras, o estudo científico deve ser holístico (do grego, "holos", "totalidade"), promovendo "a compreensão da realidade em função de totalidades integradas cujas propriedades não podem ser reduzidas a unidades menores" (CAPRA, 1999 [1982]). Da mesma forma o conhecimento deve ser sistêmico, em uma alusão à "ecologização das disciplinas" (MORIN, 2001 [1999]), capaz de compreender harmonicamente a vida, em suas mudanças culturais e religiosas, transições econômicas e sociais e em seus pontos de ruptura e mutação como em um grande sistema. A importância da vida é priorizada pela Biologia, que se mostra atualmente a ciência capaz de ultrapassar os cânones da física e da matemática do antigo paradigma e ainda oferecer o método de superação da crise ecológica: a utilização econômica da "natureza viva", combinável geneticamente e reproduzível em laboratório, e não mais uma base energética em materiais fossilizados de antigas eras geológicas. Este novo paradigma nasce calcado nas mesmas propostas da sustentabilidade, obedecendo a uma racionalidade ambiental (LEFF, 2001 [2000]) como fundamento para a reconstrução do mundo. O retorno a uma concepção de natureza enquanto "physis" (pré-socrática) — dinâmica, inteligente, não-caótica (PORTOGONÇALVES, 2000 [1989]) — parece balizar um falso entendimento de maior harmonia entre sociedade e meio ambiente. A grande questão que colocamos é que este novo paradigma, em fase de gestação, está sendo construído sob os auspícios do pensamento dominante com o interesse de contornar as grandes crises da atualidade sem atingir a origem do problema: o caráter destrutivo e exploratório do sistema capitalista, em relação às classes submissas e à própria natureza utilizada enquanto combustível. Está aberto o caminho para um novo paradigma com interesses hegemônicos, cuja epistemologia complexa e multifacetada esconde seus reais interesses.
} 
Com a supressão da monolítica ordem ambiental baseada nos recursos findáveis, a biodiversidade e a biotecnologia mostram-se imprescindíveis para a execução um renovado modelo (idem). E o Desenvolvimento Sustentável surge como o elo entre o novo e o antigo, entre o obsoleto e a nova teia de significações, representando um lento, mas irreversível caminho de mudança na relação entre sociedade e natureza travada no interior do capitalismo ${ }^{8}$, ancorada na atual conscientização global da importância dos recursos naturais para a saúde econômica vigente.

A crise desta industrialização vigorosa, apoiada em um paradigma em processo de refluxo, torna plenamente compreensível o que Robert Kurz identificou como o "colapso da modernização", cujo intento foi o de prescrever o esfacelamento das bases da sociedade industrial capitalista. Este autor, que criticou asperamente as nações que adotaram o "socialismo de caserna", entre outros motivos, por ressaltar a grande influência do modelo industrial capitalista nas mesmas, compreende que a própria derrocada do socialismo real fez parte de um processo de crise ainda maior, de todo o sistema mundial. Kurz vislumbra uma provável catástrofe econômica próxima, pois entende que vivemos um momento de profunda diminuição global da capacidade de poder aquisitivo, que atinge todos os países, mas principalmente as nações mais poderosas (KURZ, 1992 [1991]). Isto ocorrerá por causa de uma grande crise do mundo do trabalho, manifestada pela subserviência do trabalhador às necessidades do capital, através da agonia do trabalho abstrato - aquele que Marx entende como criador de valor de troca, onde o trabalhador apaga sua individualidade (MARX, 1977

\footnotetext{
${ }^{8}$ O Modo de Produção Capitalista, como sabemos, baseia-se na produção de mercadorias, onde a transformação do dinheiro (medida para troca) em capital ocorre mediante a fórmula geral $D-M-D^{\prime}$, que acaba sendo a gênese da ocorrência do capital, pois se torna o mecanismo (um processo permanente) de acumulação. O objetivo é a extração da mais-valia, que se configura como a riqueza retirada, de forma alienada, sobre o trabalho humano - que também se transforma em mercadoria - e passa a ser considerado trabalho abstrato (sem consciência de seu valor real). Entendemos que a absorção da mais-valia sobre o trabalho humano reflete-se também sobre a natureza, com a expansão global de sua apropriação em prol do valor-de-troca (que não contempla as necessidades da coletividade, mas sim do lucro). O trabalho, enquanto produção de coisas úteis para preenchimento das necessidades humanas (SMITH, 1988 [1984]) e também o aprofundamento dos laços entre os membros da sociedade através da cooperação (ENGELS, 1978 [1884]), torna-se alienado sob os auspícios do capitalismo, pois os trabalhadores não se reconhecem em seu trabalho, e este não mais serve para satisfação de suas necessidades. Além disso, o trabalho deixa de ser interação metabólica (SMITH, 1988 [1984]) entre homem e natureza, e passa a ser mercadoria. No Capitalismo, o trabalho é uma mercadoria (MARX e ENGELS, 2001 [1846]), bem como a natureza, que é entendida como algo externo aos homens, e assim toda a produção fica voltada eminentemente para o lucro. Logicamente, não acreditamos ser possível modificar profundamente esta relação exploratória, onde é aplicado um valor-de-troca nos homens, na natureza e no trabalho. A mudança que apontamos é em relação ao território, com um maior cuidado em relação aos estoques de naturezacombustível necessários para a produção de mercadorias.
} 
[1859]) ${ }^{9}$. E, como ensinou Lefebvre, o resultado do trabalho abstrato é a criação de espaços abstratos, onde prevalece o valor de troca (LEFEBVRE, 1974).

Outro autor que enxerga um horizonte sombrio para a ordem industrialista é Anthony Giddens ${ }^{10}$ que, em conjunto com Ulrich Beck e Scoth Lash, escreve sobre a urgência de uma “modernização reflexiva”. Giddens vem constantemente apontando seus receios quanto aos descaminhos do industrialismo ${ }^{11}$ e da era moderna, destacando o fato de que vivemos em uma “sociedade de risco" (GIDDENS, 1991 [1990], 1997 e 2000) onde mesmo a aceleração de descobertas técnicas e científicas não causa mais segurança e certeza de melhorias na vida cotidiana. Esse risco, ou melhor, esse conjunto de riscos característicos da modernidade, pode ser sintetizado na depressão extrema dos mecanismos de crescimento econômico, nos conflitos de grandes escala (ou mesmo nucleares), no aumento de sistemas totalitários e na deterioração ou, em maior grau, nos desastres ecológicos (GIDDENS, 1991 [1990]) cada vez mais eminentes.

Apesar das diferenças entre suas filiações teóricas, Kurz e Giddens evidenciam o quanto esta transição entre o antigo e o novo paradigma é lenta, extremamente complexa e muito longe de ser idílica. A supressão de uma grave crise, de fato, não é simples, ainda mais quando confrontamos o mal-estar de um período rígido que suplantou o tempo da natureza e criou uma violência contra a própria atividade biológica. Vivemos um "stress da modernidade" (CHESNEAUX, 1996 [1989]), onde a tecnologia onipresente afeta de forma direta o ritmo de nosso tempo.

O colapso da modernização possui uma relação incestuosa com o limite da concepção de desenvolvimento, e funciona, em nosso entendimento, como termômetro da crise da sociedade industrial. Ressaltamos esta simbiose entre desenvolvimento e modernização, pois analisamos a performance econômica, social e (por que não) epistêmico-teórica do capitalismo atual. A obsolescência e o equívoco da equação desenvolvimento = modernização (vide OLIVEIRA, 1972) não conduz à formulação de alternativas, de maneira que o debate sobre a superação dos anátemas ecológicos do industrialismo restrinja-se a aplicação de cuidados

\footnotetext{
${ }^{9}$ Encontramos um maior aprofundamento desta argumentação sobre o "trabalho abstrato" nos escritos de Robert Kurz através da leitura da obra de Gaudêncio Frigotto (FRIGOTTO, 2000 [1995]).

${ }^{10} \mathrm{Na}$ verdade, o autor entende que sua visão de risco "atravessa as fronteiras entre otimismo e pessimismo, (...) pois [o risco] reenergiza nossas vidas e está no centro dos dilemas que enfrentamos" (GIDDENS, 2000). Ou seja, o risco não apresentaria caráter sombrio, mas sim uma perspectiva positiva de no seu enfrentamento.

${ }^{11} \mathrm{O}$ autor não nega a inter-relação entre Industrialismo e Capitalismo, mas considera que devemos enxergá-los como "feixes organizacionais" ou "dimensões diferentes" (GIDDENS, 1991:61 [1990]), onde o capitalismo apresenta-se como um subtipo específico das sociedades modernas em geral (idem, p. 62).
} 
ambientais, sem que se superem as verdadeiras contradições da concepção de desenvolvimento conjugada com modernização. Como ensina Souza, nesta época de "fadiga teórica", mesmo com todos os anacronismos do sistema capitalista, ocorre uma reabilitação da idéia de desenvolvimento / modernização como solução dos problemas centrais (SOUZA, 1996:13).

Logo, compreendemos que o advento de uma realidade que exceda os limites da lógica mecânica do industrialismo não trará consigo mutações profundas nas entranhas do sistema capitalista. Ao contrário, o que ocorre é um suntuoso processo de re-ordenamento, notadamente no processo produtivo e no sistema financeiro, onde novas adjetivações do desenvolvimento - como sustentável - não atingem o âmago da questão, que seria (do ponto de vista crítico) uma transformação profunda nos próprios valores outorgados. Estas reconfigurações teóricas possuem grande poder de persuasão, mas também apresentam limites intrínsecos às suas próprias formulações.

\section{Espaço Geográfico e Desenvolvimento Sustentável: Transformações em Curso}

A consecução do Desenvolvimento Sustentável desponta como superação de problemas ulteriores de outro modelo de desenvolvimento através de um processo de reordenamento. Neste panorama, o modelo anterior, insustentável, está sendo substituído paulatinamente por um modelo de Desenvolvimento Sustentável, que pode ser compreendido a partir da observação do espaço geográfico sob quatro feições:

[1] O atual modelo de desenvolvimento capitalista vem paulatinamente destruindo as reservas naturais, de maneira que gerou o perigo próximo de escassez irreversível de determinadas matérias-primas (BRITO e RIBEIRO, 2003; RATTNER, 1992). Isto é, o modelo de industrialização fundamentado na lógica mecanicista e repetitiva, onde a natureza é um combustível utilizado em velocidade de reprodução fabril, está próximo de encontrar seu limite físico de manutenção, e assim, emerge uma série de políticas baseadas na construção de áreas de proteção ambiental. Novos objetos são edificados no espaço geográfico, oriundos do reflorestamento (uma segunda natureza em acepção literal?!) e da criação das reservas de preservação e conservação ecológica. Evidentemente, se protegerá o que for mais importante para o capital, muitas vezes ao custo de "desnaturalização" do homem, como no caso da 
expulsão das comunidades tradicionais das áreas de preservação florestas (DIEGUES, 2004 [1996]);

[2] Este mesmo padrão industrialista adotado pelo modo de produção capitalista é também responsável pelos rejeitos e resíduos poluentes, que colocam em risco a atmosfera, o solo, as águas marinhas e fluviais e toda forma de vida. A poluição, em suas diversas formas, propiciou uma quantidade incomum de novas doenças e distúrbios, parecendo caminhar para a destruição completa de certos ecossistemas e, num futuro incerto, para o próprio esgotamento do modo atual de vida urbano-industrial. Com o advento do Desenvolvimento Sustentável, o processo de esfacelamento das grandes plantas industriais (originando os tecnopólos) foi acrescido do procedimento que podemos denominar de "chancelamento verde". As novas fábricas, marcadas pelo enxugamento e flexibilidade de trabalho do operariado, passam a investir em teconologias clean, com mecanismo de filtragem de poluentes em suas diversas formas. Se nos ativermos ao caso da C.S.N. em Volta Redonda, observaremos a adoção de 130 medidas ambientais obrigatórias no âmbito do processo de sua privatização. Porém, não houve nenhuma contrapartida em relação aos postos de trabalho obliterados (OLIVEIRA, 2006);

[3] O modelo de cidade formulada a partir do industrialismo capitalista enquanto locus produtivo e administrativo deste sistema político-econômico tem seu meio ambiente convertido em fator de crise (SANTOS, 1996 [1987]), de maneira que o conjunto formado pelos graves problemas de habitação, saneamento básico, qualidade do ar, água e do solo urbanos, a extrema segregação e exclusão social, e também as dificuldades que perpassam a saúde e educação dos moradores tornaram o espaço urbano essencialmente insustentável. Em contraposição a esta crise urbana oriunda da própria expansão da cidade capitalista, um novo modelo de cidade sustentável se evidencia: os problemas ecológicos recebem tratamento, mas os problemas sociais são ocultados por uma nova estética urbana multicolorida, baseada na sustentabilidade e qualidade de vida, e na construção de discursos ideológicos baseados no apelo da forma e da paisagem;

[4] Por fim, torna-se insustentável a capacidade de crença, em uníssono e de maneira acrítica, na ideologia do progresso. Ela é um elemento essencial para a hegemonia capitalista, de onde foi gestado o fundamento teórico-metodológico da atual sociedade industrial (FURTADO, 1998 [1974]), funcionando também como a fórmula encontrada para a efetivação de um aumento total do controle sobre a natureza e a sociedade através da técnica e da ciência 
(CHAUÍ, 1982 [1980]). Contudo, os constantes reversos da evolução técnica criaram um aumento real das preocupações para com suas conseqüências. Desta forma, a ideologia do desenvolvimento cede lugar à ideologia do desenvolvimento sustentável: se novos objetos geográficos são erigidos sob a tutela deste novo modelo, um série de novas ações são baseadas neste novo padrão ecológico, desde a separação do lixo, os processos de reciclagem e reutilização, as campanhas de educação ambiental, a prática de atividades como o ecoturismo e caminhadas ecológicas, entre tantos outros. Vale ressaltar que mesmo estas ações geram novos objetos, como áreas de incineração e tratamento do lixo, escolas e fóruns ambientais e hotéis, clubes e resorts baseados no eco-lazer.

Indiscutivelmente, existem profundos vínculos entre o Espaço Geográfico, o Território e o Desenvolvimento Sustentável.

\section{Reflexões para Debate}

Historicamente, a Geografia sempre esteve ligada às questões relativas ao espaço e ao território. Se antes de sua institucionalização "engenheiros-geógrafos" acompanhavam as expedições napoleônicas e mapas eram encomendados pelos impérios visando interesses econômicos e políticos (GODLEWSKA, 1989; LIVINGSTONE, 1992), após a institucionalização ela continuava ligada ao poder e à política ao redor dos territórios em disputa na Europa e nas Colônias. A criação da cátedra de Geografia Colonial na Sorbonne é o maior desses sintomas (DUBOIS, 1894).

Em nossos dias, a renovação da Geografia e dos conceitos de espaço geográfico e território passa pela dimensão assumida pelo desenvolvimento sustentável. A "velha" natureza ressurge no discurso de geógrafos e cientistas sociais não mais como instrumento de argumentações organicistas e deterministas, mas sim enquanto elemento central na construção de novas práticas sociais, políticas e identitárias. No limite, ela é a base para a edificação de um novo mundo; a pedra filosofal para o surgimento de um novo Homem.

Como espaço geográfico é natureza transformada e território é natureza atual e em potencial, não há a menor possibilidade de que tais categorias não sejam evocadas em uma reflexão sobre o desenvolvimento sustentável. De uma forma ou de outro, o desenvolvimento sustentável contribui para a crítica dos discursos que pregam o fim dos territórios (RIBEIRO, 2008), revelando que o mundo virtual em que mergulhamos nas últimas duas décadas é 
incapaz de prescindir dos fundamentos mais rudimentares da vida humana: água, ar, solo, vegetação, agricultura. Nesse sentido, talvez devamos reconhecer de uma vez por todas que a compreensão da vida social passa, necessariamente, por uma profunda leitura de seus componentes espaciais e territoriais.

Portanto, trata-se de um tema geográfico par excellence, afetando tanto o planejamento espacial de cidades e municípios (as Agendas 21 locais) quanto o planejamento territorial dos Estados Nacionais (as políticas públicas para o meio ambiente não constam das Cartas Constituicionais de países como o Brasil?). Sob esse ponto de vista, o desenvolvimento sustentável explicita o caráter político da gestão e do uso do espaço e do território, ressignificando os recursos naturais que, de agora em diante, devem ser preservados e conservados não somente para o presente, mas também e fundamentalmente "para as gerações futuras" (OLIVEIRA, 2009).

Tudo leva a crer que os embates de outrora deram lugar a um suposto consenso. Afinal, quem é contra o desenvolvimento sustentável? Ele significa um conjunto de práticas integrantes de um novo tipo de gestão do espaço e do território em curso, já que compreende a implantação de novos objetos (áreas de proteção ambiental, estações de tratamento de água e esgoto, reflorestamento, instalação de fábricas ecologicamente corretas, entre outros) e novas ações (gestão da natureza, políticas públicas para o meio ambiente, reciclagem, arborização, educação ambiental ostensiva etc.).

Ainda é possível negar o papel político do espaço e do território?

\section{Referências Bibliográficas}

AGENDA 21. CONFERÊNCIA DAS NAÇÕES UNIDAS SOBRE MEIO AMBIENTE E DESENVOlVIMENTO. A Agenda 21. Brasília: Senado Federal, Subsecretaria de Edições Técnicas, 1996.

BARRIOS, Sonia. A produção do espaço. In: SANTOS, Milton, SOUZA, Maria Adélia de (orgs.). A Construção do Espaço. São Paulo: Nobel,1986.

BRITO, Daniel Chaves de, RIBEIRO, Tânia Guimarães. A modernização na era das incertezas: crise e desafios da teoria social. Ambiente \& Sociedade, Campinas, vol.6, $\mathrm{n}^{\circ} .1$, p.147-164, 2003. 
BRUNDTLAND, Gro Harlem. COMISSÃO MUNDIAL SOBRE MEIO AMBIENTE E DESENVOLVIMENTO - 1988. Nosso Futuro Comum (Relatório Brundtland). Rio de Janeiro, Fundação Getúlio Vargas, 1988.

CAPRA, Fritjof. O Ponto de Mutação. 22ª ed. São Paulo, Editora Cultrix, 1999 (1982).

CASTELLS, Manuel. A Sociedade em Rede. Rio de Janeiro: Paz e Terra, 1999.

CHAUÍ, Marilena. O que é Ideologia. 9a ed. São Paulo, Editora Brasiliense, 1982 (1980).

CHESNEAUX, Jean. Modernidade-Mundo: Brave modern world. Petrópolis: Vozes, 1996 (1989).

DIEGUES, Antonio C. O Mito Moderno da Natureza Intocada. São Paulo: Hucitec, 2004 (1996).

DUBOIS, Marcel. Leçon inaugurale du cours de Géographie Coloniale. Annales de Géographie, vol. 10, 121-137 (1894).

ENGELS, Friedrich. Dialéctica da Natureza. Lisboa: Presença, 1978 (1884).

FRIGOTTO, Gaudêncio. A Educação e a Crise do Capitalismo Real. $4^{\mathrm{a}}$ ed. São Paulo: Cortez, 2000 (1995).

FURTADO, Celso. O Mito do Desenvolvimento Econômico. $2^{\text {a }}$ ed. Rio de Janeiro: Paz e Terra, 1998 (1974).

GIDDENS, Anthony. As Conseqüiências da Modernidade. São Paulo, Editora UNESP, 1991 (1990).

A vida em uma sociedade pós-tradicional. In: BECK, Ulrich, GIDDENS, Anthony, LASH, Scott. Modernização Reflexiva: Política, Tradição e Estética na Ordem Social Moderna. São Paulo, Editora da Universidade Estadual Paulista, 1997.

, PIERSON, Christopher. Conversas com Anthony Giddens: O Sentido da Modernidade. Rio de Janeiro: Editora FGV, 2000.

GODLEWSKA, Anne. Traditions, crisis and new paradigms in the rise of the modern french discipline of Geography 1760-1850. Annals of the Association of American Geographers, vol. 79, n. 2, jun, 1989.

HAESBAERT, Rogério. O mito da desterritorialização. Do “fim dos territórios” à multiterritorialidade. Rio de Janeiro: Bertrand Brasil, 2007 (2004).

KANT, Immanuel. Estética Transcendental. In: KANT, Immanuel. Crítica da Razão Pura. São Paulo: Martin Claret, 2002 (1781). 
KURZ, Robert. O Colapso da Modernização: da derrocada do Socialismo de caserna à crise da economia mundial. Rio de Janeiro: Paz e Terra, 1992 (1991).

LEFEBVRE, Henri. O Direito à Cidade. São Paulo: Centauro, 2001 (1968).

A Revolução Urbana. Belo Horizonte: Editora da UFMG, 1999 (1970).

—. Espacio y Politica. Barcelona, Ediciones Península, 1976 (1972).

—. La production de l'espace. Paris: Anthropos, 1974.

LEFF, Enrique. Epistemologia Ambiental. 3a ed. São Paulo: Cortez, 2001 (2000).

LIVINGSTONE, David. The geographical tradition. Episodes in the history of a contested enterprise. Malden: Blackwell, 1992.

MARX, Karl. Contribuição à crítica da Economia Política. São Paulo: Martins Fontes, 1977 (1859).

, ENGELS, Friedrich. A Ideologia Alemã. São Paulo: Martins Fontes, 2001 (1846).

MASSEY, Doreen. Pelo Espaço: uma nova política da espacialidade. Rio de Janeiro: Bertrand Brasil, 2008 (2005).

MOREIRA, Ruy. As Categorias Espaciais da Construção Geográfica das Sociedades. Geographia, Revista do Programa de Pós-Graduação em Geografia da UFF. Niterói/Rio de Janeiro, UFF/EGG, Ano III, nº 5, 2001

. O Espaço e o Contra-Espaço: Sociedade Civil e Estado, Privado e Público na Ordem Espacial Burguesa. In: Território Territórios. Programa de Pós-Graduação em Geografia-PPGEO-UFF/AGB - Niterói, 2002.

O Círculo e a Espiral: Para a Crítica da Geografia que se Ensina - I. Niterói / RJ, Edições AGB - Niterói, 2004.

MORIN, Edgar. Ciência com Consciência. Rio de Janeiro: Bertrand Brasil, 1996.

A Cabeça Bem-Feita: Repensar a Reforma, Reformar o Pensamento. $3^{\text {a }}$ ed. Rio de Janeiro: Bertrand Brasil, 2001 (1999).

NEWTON, Isaac. O Peso e o Equilíbrio dos Fluidos. In: NEWTON, Isaac. Princípios Matemáticos. Óptica. O Peso e o Equilíbrio dos Fluidos (Coleção Os Pensadores). São Paulo: Abril Cultural, 1979.

OLIVEIRA, Francisco de. Crítica à razão dualista. Estudos Cebrap, n. 2 (1972).

OLIVEIRA, Leandro Dias de. A Construção do Desenvolvimento Sustentável na Cidade de Volta Redonda: Um Estudo sobre Reestruturação do Território e Ideologia. 2006. 
Dissertação (Mestrado em Geografia). Departamento de Geografia do Instituto de Geociências, Universidade do Estado do Rio de Janeiro, Rio de Janeiro, 2006.

A construção do desenvolvimento sustentável sob a égide do neoliberalismo: um estudo sobre a economia política da crise ambiental. In: 5. ${ }^{\circ}$ CEMARX - Colóquio Internacional Marx e Engels. Campinas: UNICAMP, 2007.

Teses sobre o Desenvolvimento Sustentável. Revista Iluminart, v. 1, p. 242-256, 2009.

PORTO-GONÇAVES, Carlos Walter. Os (Des) Caminhos do Meio Ambiente. $7^{\text {a }}$ ed. São Paulo: Contexto, 2000 (1989).

PRIGOGINE, Ilya, STENGERS, Isabelle. A Nova Aliança. Brasília: Editora da UNB, 1991 (1979).

PROTOCOLO DE QUIOTO E LEGISLAÇÃO CORRELATA. Brasília, Senado Federal, Subsecretaria de Edições Técnicas. Coleção Ambiental, vol. 3 (1988-1992).

QUAINI, Massimo. Marxismo e Geografia. Rio de Janeiro: Paz e Terra, 1979.

RATTNER, Henrique. Tecnologia e Desenvolvimento Sustentável. In: HOYOS, Juan L. Bardález. (Org.) Desenvolvimento Sustentável: Um Novo Caminho? Belém, UFPA, NUMA, 1992.

RIBEIRO, Guilherme. As apropriações do espaço no pensamento de Eric Hobsbawm: a epistemologia da Geografia vista sob o olhar do outro. Dissertação de mestrado. Niterói: PPGE-UFF, 2004.

Modernidade e espaço, pós-modernidade e mundo: a crise da Geografia em tempos de Globalização. Diez años de cambios en el mundo, en la Geografía y en las Ciencias Sociales, 1999-2008. Actas del X Coloquio Internacional de Geocrítica, Universidad de Barcelona, 26-30 de mayo de 2008. <http://www.ub.es/geocrit/-xcol/154.htm>.

RODRIGUES, Arlete Moysés. Espaço, Meio Ambiente e Desenvolvimento: Releituras do Território. Terra Livre, AGB, n. ${ }^{\circ}$ 11-12, 1992.

SANTOS, Boaventura de Sousa. Um Discurso sobre as Ciências. $8^{\text {a }}$ ed. Porto: Afrontamento, 1996 (1987).

SANTOS, Milton. Society and space: social formation as theory and method. Antipode, 9 (1), 1977.

Por uma Geografia Nova. São Paulo: Hucitec/Edusp, 1978. 
A Natureza do Espaço. Técnica e Tempo. Razão e Emoção. São Paulo: Edusp, 2002 (1996).

SOUZA, Marcelo José Lopes de. O Território: sobre Espaço e Poder, Autonomia e Desenvolvimento. In: CASTRO, Iná Elias de, CORRÊA, Roberto Lobato, GOMES, Paulo César (orgs.). Geografia: Conceitos e Temas. Rio de Janeiro: Bertrand Brasil, 1995.

A teorização sobre o desenvolvimento em uma época de fadiga teórica, ou: sobre a necessidade de uma "teoria aberta" do desenvolvimento socioespacial. Território, UFRJ, vol. $1, \mathrm{n}^{\mathrm{o}} 1,1996$.

SMITH, Neil. Desenvolvimento Desigual: Natureza, Capital e a Produção do Espaço. Rio de Janeiro, Bertrand Brasil, 1988 (1984).

—. Geografía, diferencia y las políticas de escala. Terra Livre, São Paulo, ano 18, nº 19, jul./dez., 2002.

SOJA, Edward. Geografias Pós-Modernas: a reafirmação do espaço na teoria social crítica. Rio de Janeiro: Jorge Zahar Editor, 1993 (1992).

SOUZA, Marcelo J. L. de. "Espaciologia": uma objeção (Crítica aos prestigiamentos pseudocríticos do espçao social). Terra Livre, n. 5, 1988.

VIDAL DE LA BLACHE, Paul. O Princípio da Geografia Geral. Geographia, Revista do Programa de Pós-Graduação em Geografia da UFF, nº 6, ano III, 2002 (1896).

VIRILIO, Paul. O Espaço Crítico e as Perspectivas do Tempo Real. São Paulo: Editora 34, 1993 (1984).

Enviado para publicação em março de 2010.

Aceito para publicação em junho de 2010. 